\title{
Prevalence and determinants of the dangerous selfie among medical and nursing students: a cross-sectional study from eastern India
}

Priyamadhaba Behera ${ }^{\dagger}$, Arvind Kumar Singh ${ }^{*}$, Vikas Bhatia, P. S. Preeti, Rishav Kumar, Satyajeet Das, Rupesh Tholia, Ritajyoti Ghosh, Sandeep Kumar, K. S. Safiya, Rojismita Purohit and Raman Bansal

\begin{abstract}
Background: Globally, there has been an exponential rise in smartphone use and selfie taking among youth. To make selfies exciting, dangerous selfies are often taken that may lead to catastrophic consequences, including death. This study aims to estimate the prevalence of dangerous selfies and to determine the factors associated with dangerous selfies among medical and nursing students in India.

Methods: The study was conducted at the All India Institute of Medical Sciences (AllMS), Bhubaneswar, India, in April-August 2018. The inclusion criteria were students enrolled in the Bachelor of Medicine and Bachelor of Surgery (MBBS) and nursing courses of AlIMS, Bhubaneswar. Students who did not use smartphones were excluded from the study. The interview schedule and Selfitis Behaviour Scale (SBS) were used to collect information on sociodemographic variables, smartphone use and variables related to selfies and dangerous selfies. Forward stepwise logistic regression was undertaken with the probability of entry and removal as 0.05 and 0.10 , respectively.

Results: Of 633 eligible participants, 595 were included in the study. The mean (SD) age of the participants was 21.2 (1.6) years. More than half (56.8\%) of the participants were female, 384 (64.5\%) were medical students and 211 (35.5\%) were nursing students. Nearly two-thirds of the participants (70.6\%) preferred to take selfie. One hundred thirty three $(40.3 \%)$ of the participants posted selfies on social media daily. The prevalence of dangerous selfies was 8.74\% (95\% Cl: 6.73-11.28). Eight injury episodes while taking selfies were reported by seven (1.2\%) participants. Being male (AOR 4.96, 95\% Cl 2.53-9.74), posting selfies on social media daily (AOR 3.33, 95\% Cl 1.71-6.47) and an SBS score $>75$ (AOR 4.97, 95\% Cl 1.43-17.28) were independent predictors of dangerous selfies.

\footnotetext{
* Correspondence: arvind28aug@gmail.com

${ }^{\dagger}$ Priyamadhaba Behera and Arvind Kumar Singh have contributed equally and are primary authors of the study.

Department of Community Medicine and Family Medicine, AllMS,

Bhubaneswar 751019, India
}

(c) The Author(s). 2020 Open Access This article is licensed under a Creative Commons Attribution 4.0 International License, which permits use, sharing, adaptation, distribution and reproduction in any medium or format, as long as you give appropriate credit to the original author(s) and the source, provide a link to the Creative Commons licence, and indicate if changes were made. The images or other third party material in this article are included in the article's Creative Commons. licence, unless indicated otherwise in a credit line to the material. If material is not included in the article's Creative Commons licence and your intended use is not permitted by statutory regulation or exceeds the permitted use, you will need to obtain permission directly from the copyright holder. To view a copy of this licence, visit http://creativecommons.org/licenses/by/4.0/ The Creative Commons Public Domain Dedication waiver (http://creativecommons.org/publicdomain/zero/1.0/) applies to the data made available in this article, unless otherwise stated in a credit line to the data. 
(Continued from previous page)

Conclusion: Nearly one in ten medical and nursing students reported having taken a dangerous selfie, and one in one hundred reported having been injured while attempting to take a selfie. Being male, posting selfies on social media daily and an SBS score $>75$ were independent predictors of dangerous selfies. Further research is required to identify the community burden of dangerous selfies and to develop strategies to prevent selfie-related fatalities among youths.

Keywords: Selfie, Dangerous selfie, Selfitis behaviour scale, Medical and nursing students, India

\section{Background}

The present age can undoubtedly be branded as the era of advancements in mobile technologies. There are approximately 2.5 billion smartphone users worldwide and 650 million users in India [1]. In the last three decades, advancements in mobile technology have led to new features, such as the selfietool, online gaming, gambling, and shopping [2]. The selfietool, in particular, has become a trend and a medium of self-representation, especially among young people.

The Oxford English Dictionary defines a "selfie" as a photograph that one has taken of oneself, generally with a smartphone or a web camera, that is often uploaded to a social media platform [3]. The word selfie has become so common that the Oxford English Dictionary declared it "the Word of the Year" in 2013 [4]. According to a study by Lee and Sung (2016), smartphone users take approximately 93 million selfies each day [5].

According to the "Mobile Technology and Home Broadband 2019" survey performed by the Pew Research Center, $96 \%$ of those aged between 18 and 29 years in the U.S. owned a smartphone [6]; another study estimated that $98 \%$ of the participants (aged 18 to 24 ) took selfies, and $69 \%$ tended to share selfies 3 to 20 times daily [7]. A similar study conducted among students in the city of Mumbai revealed that $42.6 \%$ regularly took selfies, while $18.1 \%$ of girls and $15.2 \%$ of boys took an average of more than four selfies per day [8]. A survey by Era Dutta et al. reported that the prevalence of "addiction to selfie taking" was $13 \%$ among adolescents in Mumbai [8]. A cross-sectional study conducted among medical and nursing students in Bangalore, India, estimated that the majority of students took selfies, and nearly one-quarter of the students had a condition termed selfitis (the obsessive taking of selfies) [9]. Certain studies have revealed that the habit of taking selfies can be linked to grandiosity, narcissism and dysmorphic disorder [10]. Currently, to add excitement to their selfies and to portray themselves as what young people deem "cool," people are increasingly taking selfies in situations that can be potentially dangerous to gain attention on social media $[11,12]$. These situations may lead to fatal consequences. There are various apps and blogs that challenge people to take selfies in difficult situations, for example, underwater selfie challenges. People often risk their lives to respond to these challenges, which can be potentially harmful [13, 14]. Such risks can be observed by looking at images posted even in the face of natural disasters, when people should be protecting themselves and helping others. According to a BBC report published on 4 October 2018, 259 people died while taking selfies in 2018 alone [15]. The deaths of Gavin Zimmerman (New South Wales, Australia) [16] and Tomer Frankfurter (Yosemite National Park) [16] brought this issue, which had previously been unheardof, into the limelight. Selfie deaths are often underreported or not reported as the official cause of death. The highest number of selfie injuries and deaths has been reported in India, accounting for approximately 50\% of the total selfie deaths reported worldwide, followed by Russia, the United States, and Pakistan [17]. The ratio of casualties to incidents in India is double that in other countries [17] Three out of four selfie deaths occur in the youngest age group, less than 25 years [18]. There has been an exponential rise in selfie taking among youths as well as among medical and nursing students in India [9, 19]. However, the burden of dangerous selfies and the associated risk factors remains unexplored in the literature. This study aims to estimate the prevalence of dangerous selfies and to determine the factors associated with dangerous selfies among medical and nursing students in India.

\section{Methods \\ Participants}

We conducted a cross-sectional study among medical and nursing students of the All India Institute of Medical Sciences (AIIMS) (hereafter referred to as 'the institute') in Bhubaneswar, Odisha, India, in April-August 2018. AIIMS Bhubaneswar was chosen for the study setting because, as a central institute, it has student representatives from all over India, and almost all the students have access to a smartphone, thus ensuring the feasibility of the study. The inclusion criteria were students enrolled in the Bachelor of Medicine and Bachelor of Surgery (MBBS) and nursing courses at the institute. Students who did not use smartphones were excluded from the study. There were no available prevalence 
studies regarding dangerous selfie behaviour among young adults. We used the prevalence of addiction to selfies as a proxy for the act of taking a dangerous selfie and estimated the sample size accordingly. Taking the prevalence as $13 \%$ [8], alpha $=5 \%$, beta $=20 \%$, the suitable sample size was calculated to be 643 .

\section{Measures}

In our study, a selfie is defined as self-portrait photography of oneself (or oneself with other people) taken with a camera or a camera phone held at arm's length or pointed at a mirror and usually shared through social media. Social media is defined as websites and applications, such as Facebook, Twitter, WhatsApp, and Instagram,that enable users to create and share content or to participate in social networking. A dangerous selfie is defined as a selfie taken in a situation that is potentially dangerous to oneself and others in the vicinity. These situations include posing amid heavy traffic while driving, while diving, with a vicious animal (wildlife selfie), at high-altitude edges (such as mountaintops and cliffs) or on megastructures, during natural disasters, and in front of burning buildings. A structured interview schedule was developed based on a review of the literature.

The interview questions were pilot-tested among 20 students and then finalized. The interviews were used to collect information on sociodemographic variables, smartphone use and variables related to selfies and dangerous selfies. Participants were considered to take selfies daily and post selfies on social media daily if they had done so for the previous 15 days or more. The dangerous selfies was considered when the participants had ever taken one. The Selfitis Behaviour Scale (SBS) is a validated tool for the assessment of selfie-related behaviour. The scale was developed by Balakrishnan \& Griffiths [20]. It has six components: environmental enhancement, social competition, attention-seeking, mood modification, self-confidence, and social conformity. It consists of 20 items. The domains of environmental enhancement and social competition each contain four items, and the domains of attention-seeking, mood modification, self-confidence, and subjective conformity each contain three items. For example, "Taking selfies gives me a good feeling to better enjoy my environment" is related to assessing environmental enhancement. Similarly, "Taking different selfie poses helps increase my social status" is related to social competition. The response to each item was rated on a 5-point Likert scale (1 - strongly disagree; 2 - disagree; 3 - neither agree nor disagree; 4 - agree; 5 - strongly agree). The total scores ranged from 20 to 100 . The behaviour was categorized as normal, borderline, acute and chronic selfitis with scores ranging from 20 to 40,40 to 60,60 to 80 , and 80 to 100 , respectively [9].

\section{Procedures}

Ethical approval was obtained from the Institutional Ethics Committee, All India Institute of Medical Sciences, Bhubaneswar (Ref Number: T/IM-NF/CM\&FM/17/47). Permission was received from the dean of the institute, and all medical (400) and nursing students (235) were contacted. The purpose of the study was explained to the students through participant information sheets. Written informed consent was obtained from participants above 18 years of age. Written informed assent was obtained who were between 17 and 18 years of age. Written informed consent was also obtained from the dean of the institute. The Institutional Ethics Board approved this consent procedure. Then, the structured interview schedule and SBS were privately administered to the medical and nursing students in the group. Two additional visits were made to the student hostels to contact participants who were absent during the first visit. The participants who were absent even after the three visits (made 1-2 weeks apart) were categorized as non-respondents and excluded from the study. The participants who had positive scores for dangerous selfies were referred to the psychiatric clinic.

\section{Data analysis}

The data were entered into Excel. The analysis was performed in SPSS 16.0. The results were reported as proportions with a $95 \%$ confidence interval $(95 \% \mathrm{CI})$ for the reported dangerous selfies. The mean (SD) was reported for continuous variables. Univariate and multivariate analyses were performed to examine the association of variables with dangerous selfies. The strength of association was measured as an odds ratio. A value of $p<0.05$ was considered significant. Logistic regression was performed for the variables age, gender, occupation, taking selfies on a daily basis, posting selfies on social media daily and SBS score. Unadjusted odds ratios and $p$-values were reported in univariate analyses. Multivariate analysis was performed for independent predictors of dangerous selfies. The variables for which $p<0.25$ in the univariate analysis were included in the multiple logistic regression. Forward stepwise logistic regression was undertaken with the probability of entry and removal as 0.05 and 0.10 , respectively [21].

\section{Results}

There were a total of 635 participants. Eighteen participants did not give consent, and 20 participants could not be contacted because of their absence despite three visits (one private visit in the group and two additional visits to the hostels) $2-4$ weeks apart. Of 597 participants who were interviewed, two were excluded because they did not use smartphones. Finally, of 633 eligible participants, 595 students participated in the study, and the 
response rate was $94 \%$. Of the 595 participants, 384 (64.5\%) were medical students, and 211 (35.5\%) were nursing students (Table 1). The mean (SD) age of the participants was 21.2 (1.6) years. The majority of the participants (91.4\%) were between 18 and 22 years old, and more than half $(56.8 \%)$ were females. Nearly twothirds of the participants (70.6\%) took selfies. Among them, $78.6 \%$ took selfies daily, $15.5 \%$ at least once a week and $5.9 \%$ only on special events/occasions.

The average number of selfies taken per day by a participant was 3.6. The average number of selfies posted by a participant per day was 1.35 . The majority (90.9\%) of those who took selfies daily took 1 to 4 selfies a day, while $1.2 \%$ took more than eight selfies a day. Of the 330 participants who took selfies daily, 133 (40.3\%) uploaded selfies on social media daily. One hundred twenty-seven participants (38.4\%) posted selfies on social media one to three times a day, while six participants (1.8\%) posted selfies on social media more than three times a day (Table 2). Approximately $8.74 \%$ (95\% CI: 6.73-11.28) of the participants admitted taking dangerous selfies. Eight injury incidents while taking selfies were reported by $7(1.2 \%)$ participants (one participant had been injured twice).

The mean (SD) SBS score was 47.1 (14.9) (Supplementary Table 1). Based on the SBS score, nearly half of the participants $(52.6 \%)$ were classified as borderline; however, 8 (1.3\%) participants had chronic selfitis, and 109 (18.3\%) participants had acute selfitis (Table 3). The highest quartile (SBS score > 75) was associated with dangerous selfies in the univariate analysis (Supplementary Table 2).

Dangerous selfies were more prevalent in the 17-22 age group (9.0\%) than in the $\geq 23$ age group (5.9\%), among males (14.4\%) than among females (4.4\%), among medical students (11.2\%) than among nursing students (4.3\%), among participants who took selfies on a daily basis $(11.2 \%)$ than among those who did not take selfies on a daily basis (5.7\%), among participants posting selfies on social media daily (15.0\%) than among those not posting selfies on social media daily $(6.9 \%)$ and among participants with an SBS score $>75$ (35.7\%) than among

Table 1 Socio-demographic characteristics of the sample $(n=595)$

\begin{tabular}{llll}
\hline Characteristics & & Frequency & \% \\
\hline Age (in completed years) & $17-19$ & 199 & 33.4 \\
& $20-22$ & 345 & 58.0 \\
& $\geq 23$ & 51 & 8.6 \\
Gender & Female & 338 & 56.8 \\
& Male & 257 & 43.2 \\
Course of study & Medical students & 384 & 64.5 \\
& Nursing students & 211 & 35.5 \\
\hline
\end{tabular}

those with an SBS score $\leq 75$ (8.1\%) (Table 4). Logistic regression analysis showed that being male (AOR 4.96, 95\% CI 2.53-9.74), posting selfies on social media daily (AOR 3.33, 95\% CI 1.71-6.47), and an SBS score $>75$ (AOR 4.97, 95\% CI 1.43-17.28) were independent predictors of dangerous selfies (Table 4). Occupation (OR $2.83,95 \% \mathrm{CI} 1.35-5.93)$ and taking selfies on a daily basis (OR 2.11, 95\% CI 1.13-3.93) were associated factors in the univariate analysis; however, these factors were not significant after adjusting for other factors in the multivariate forward stepwise logistic regression (Table 4).

\section{Discussion}

The first known selfie was taken in 1839 [22]. However, in recent years, taking personal or group selfies has become very popular among adolescents and young people [23]. Medical and nursing students are no exception. With the increase in the need to make selfies exciting and to gain attention on social media, dangerous selfies are becoming increasingly common [18]. The mass media have reported many incidents of injuries and even fatalities while taking selfies, but the scientific literature has not sufficiently explored the topic. In our study, we found that nearly one in ten participants had taken dangerous selfies, and one in one hundred participants had injured themselves while taking selfies. Temporary distraction while taking a selfie reduces a person's situational awareness, which increases risky behaviour, as the person loses the sense of danger in such situations $[11,24]$. This may explain selfie-related injuries and fatalities. Therefore, preventing dangerous selfies remains vital to avoid selfie-related injuries and fatalities.

Selfitis (the obsessive taking of selfies) as a disorder has recently attracted the attention of researchers. Nearly one-fifth of the participants in our study had selfitis. Previous studies have shown that selfitis is linked to poor work/academic performance, peer pressure, unwanted stress, unhealthy family relations, conflicts, and other problems. It may lead to complications such as low back pain, cervical spondylitis, awkward posture, frozen shoulder, and tennis elbow [25].

In our study, being male was a risk factor for dangerous selfies. A study in Poland by Sorokowski P et al. reported that narcissism was associated with men posting selfies online more than women [26]. Previous studies indicate that self-presentation, the demand for admiration, and leadership associated with narcissism among men are reasons for posting different types of selfies, including dangerous selfies [5, 27]. A comprehensive study of worldwide selfie-related accidental mortality revealed that $82 \%$ of the victims were male [18]. Similarly, a study in India by Bansal A et al. reported that $72.5 \%$ of selfie deaths occurred among males [17], which also supports 
Table 2 Distribution of participants by taking Selfies

\begin{tabular}{|c|c|c|c|}
\hline \multicolumn{2}{|l|}{ Characteristics of participants } & \multirow{2}{*}{$\begin{array}{l}\text { Frequency } \\
420\end{array}$} & \multirow{2}{*}{$\frac{\%}{70.6}$} \\
\hline Do you take selfies? $(n=595)$ & Yes & & \\
\hline & No & 175 & 29.4 \\
\hline \multirow[t]{3}{*}{ Do you take selfie daily or weekly or on special event/occasion only? $(n=420)$} & Daily & 330 & 78.6 \\
\hline & Weekly & 65 & 15.5 \\
\hline & On special event/occasion only & 25 & 5.9 \\
\hline \multirow[t]{3}{*}{ Number of selfies taken per day $(n=330)$} & 1 to 4 & 300 & 90.9 \\
\hline & 5 to 8 & 26 & 7.9 \\
\hline & $>8$ & 4 & 1.2 \\
\hline \multirow[t]{3}{*}{ Number of selfies posting on social media daily $(n=330)$} & None & 197 & 59.7 \\
\hline & At least One time to three times & 127 & 38.5 \\
\hline & More than three times & 6 & 1.8 \\
\hline
\end{tabular}

our study finding that being male is a risk factor for dangerous selfies. Impulsive action is typically greater in males than females [28]. This may be another potential reason why male sex was a risk factor for dangerous selfies.

Posting selfies on social media daily was another risk factor for dangerous selfies. Although taking selfies daily was not a risk factor for dangerous selfies, those who posted selfies daily had taken dangerous selfies. The possible link is that the appreciation associated with 'likes', 'followers' and positive comments on social media is rewarding for people with higher levels of loneliness, isolation, and insecurity [29]. Attention-seeking, communication, archiving and entertainment are the motivations for posting selfies on social media [30]. Our findings that taking too many selfies and posting them online are causes of selfie-related injuries and fatal events were consistent with the literature [18].

Based on the categories in our study, a high SBS score (highest quartile, > 75) was an independent predictor of dangerous selfies. The SBS has six components: environmental enhancement, social competition, attentionseeking, mood modification, self-confidence, and social conformity. No previous research has considered the association of the SBS score and dangerous selfies. Thus, our study suggests that the SBS may serve as a screening tool to identify the probability of dangerous selfies; however, more research is required to further delineate the role of the SBS. Selfies in themselves are not harmful, but the human behaviour that accompanies selfies can be dangerous. When taking a selfie, a person needs to ensure that he or she is in a safe place and that his or her life is not in danger. Concerns regarding selfie injuries and fatalities have already led to various actions. The government of Russia has released a full-scale marketing campaign with icons referring to dangerous selfies [31], and selfies have not been allowed in the Hong Kong Marathon since 2014 [32]. Taking dangerous selfies and posting dangerous selfies on social media should be restricted. Lack of situational awareness and overenthusiastic behaviour plays a vital role in selfie-related injuries. Hence, the implementation of "no selfie zones" in high-risk areas as well as discouraging high-risk behaviour such as taking selfies while driving may limit adverse events. "No selfie zones" are potentially dangerous spots in tourist areas that can be disastrous if public access is allowed. Many tourist areas in India, such as Nainital and Shimla, have sites such as sunset points, suicide points, and lovers' points that are mountaintops or cliffs. These sites are associated with selfie-related injuries and deaths. Mumbai and Goa are pioneer cities in implementing "no selfie zones" [33]. This approach should be encouraged. Drawing the attention of social platform giants such as Facebook, Instagram, and Google to the risks of dangerous selfies, amending their current image upload policies so that such behaviour is not rewarded by the "likes" and "thumbs-ups" of fellow users and aggressively removing selfie challenge applications from app stores will potentially help save lives and prevent injuries.

Table 3 Distribution for participants by Selfitis Behaviour Scale (SBS) score

\begin{tabular}{llll}
\hline Classification of Selfitis by SBS score & Male $\mathbf{n}(\%)$ & Female $\mathbf{n}(\%)$ & Total $\mathbf{n}(\%)$ \\
\hline Normal (20-39) & $90(35.0)$ & $75(22.2)$ & $165(27.7)$ \\
Borderline (40-59) & $129(50.2)$ & $184(54.4)$ & $313(52.6)$ \\
Acute Selfitis (60-79) & $33(12.8)$ & $76(22.5)$ & $109(18.3)$ \\
Chronic selfitis (80-100) & $5(2.0)$ & $3(0.9)$ & $8(1.3)$ \\
& $\mathbf{2 5 7 ( 1 0 0 )}$ & $\mathbf{3 3 8 ( 1 0 0 )}$ & $\mathbf{5 9 5 ( 1 0 0 )}$ \\
\hline
\end{tabular}


Table 4 Associated risk factors for "Dangerous Selfie"

\begin{tabular}{|c|c|c|c|c|c|c|}
\hline Variables & $\begin{array}{l}\text { Total number } \\
\text { of participants } \\
(n=595)\end{array}$ & $\begin{array}{l}\text { Total number of participants } \\
\text { "took selfie in a situation which } \\
\text { could be potentially dangerous" } \\
n=52(\%)\end{array}$ & $\begin{array}{l}\text { Unadjusted odd } \\
\text { ratio }(95 \% \mathrm{Cl})\end{array}$ & $P$-Value & $\begin{array}{l}\text { Adjusted odd } \\
\text { ratio }(95 \% \mathrm{Cl})\end{array}$ & $P$-value \\
\hline \multicolumn{7}{|l|}{ Age (in years) } \\
\hline $17-19$ & 199 & $18(9.0)$ & $1.59(0.45-5.63)$ & 0.464 & & \\
\hline $20-22$ & 345 & $31(9.0)$ & $1.58(0.47-5.37)$ & 0.471 & & \\
\hline$\geq 23$ & 51 & $3(5.9)$ & Reference & & & \\
\hline \multicolumn{7}{|l|}{ Gender } \\
\hline Female & 338 & $15(4.4)$ & Reference & & Reference & \\
\hline Male & 257 & $37(14.4)$ & $3.62(1.94-6.76)$ & $<0.001$ & $4.96(2.53-9.74)$ & $<0.001$ \\
\hline \multicolumn{7}{|l|}{ Occupation } \\
\hline Nursing students & 211 & $9(4.3)$ & Reference & & & \\
\hline Medical students & 384 & $43(11.2)$ & $2.83(1.35-5.93)$ & 0.006 & & \\
\hline \multicolumn{7}{|c|}{ Taking selfies on a daily basis } \\
\hline No & 265 & $15(5.7)$ & Reference & & & \\
\hline Yes & 330 & $37(11.2)$ & $2.11(1.13-3.93)$ & 0.019 & & \\
\hline \multicolumn{7}{|c|}{ Posting selfies on social media daily } \\
\hline No & 462 & $32(6.9)$ & Reference & & Reference & \\
\hline Yes & 133 & $20(15.0)$ & $2.38(1.31-4.32)$ & 0.004 & $3.33(1.71-6.47)$ & $<0.001$ \\
\hline \multicolumn{7}{|c|}{ Selfitis Behaviour Scale (SBS) score } \\
\hline SBS score (0-75) & 581 & $47(8.1)$ & Reference & & Reference & \\
\hline SBS Score (76-100) & 14 & $5(35.7)$ & $6.31(2.03-19.60)$ & 0.001 & $4.97(1.43-17.28)$ & 0.012 \\
\hline
\end{tabular}

The dangerous selfie, a vital link to selfie-related injuries and deaths, has been explored in this study, which is unique in the literature. The results of the study cannot be generalized to the young population, as the sample was limited to medical and nursing students. The possibility of recall bias cannot be excluded from this study. The self-report method, which may be prone to underreporting, was used for the assessment of the "dangerous selfie". Some potential confounders, such as internet addiction and psychosocial factors, were not included in this study. We studied 595 participants, although the calculated sample size was 643. Detailed histories of selfie injuries were not collected. We also did not elicit a detailed history of how long participants had taken selfies daily or posted selfies on social media daily (the previous 15 days or more was considered to avoid recall bias). For dangerous selfies, the criterion was whether the participants had ever taken one; however, for social media posting, it was whether they had posted for the previous 15 days or more.

\section{Conclusion}

Nearly one in ten medical and nursing students reported taking dangerous selfies, and one in one hundred reported having been injured while attempting a selfie. Being male, posting selfies on social media daily and an
SBS score $>75$ were independent predictors of dangerous selfies. Further research is required to identify the community burden of dangerous selfies among the young population. Awareness should be created among students to prevent selfie-related injuries and fatalities. "No selfie zones" should be identified and implemented at high-risk sites in tourist areas.

\section{Supplementary information}

Supplementary information accompanies this paper at https://doi.org/10. 1186/s12889-020-08785-4.

Additional file 1: Supplementary Table 1. Selfitis Behaviour Scale (SBS) score distribution for participants. Supplementary Table 2. Association of "Dangerous Selfie" with SBS score (Quartile as assumptions).

\section{Abbreviations}

AllMS: All India Institute of Medical Sciences; AOR: Adjusted Odd Ratio; $\mathrm{Cl}$ : Confidence Interval; MBBS: Bachelor of Medicine and Bachelor of Surgery; SBS: Selfitis Behaviour Scale; SD: Standard Deviation

Acknowledgements

We thank Ishani Behera (Christ University, Bangalore) for help in language editing of the manuscript.

Authors' contributions

Conceived and designed the experiments: PM and AKS. Performed the experiments: PM, AKS, PP, RK, SD, RT, RG, SK, SKS, RP, RB and VB. Wrote the paper: PM, AKS, PP and VB. Data interpretation: PM, AKS, PP, RK, SD, RT, RG, 
SK, SKS, RP, RB and VB. Critical revision to the manuscript: PM, AKS, PP, RK, SD, RT, RG, SK, SKS, RP, RB and VB. All authors have read and approved the final manuscript.

\section{Funding}

This research received no specific grant from any funding agency in the public, commercial or not-for-profit sectors.

\section{Availability of data and materials}

The dataset is available with corresponding authors and can be availed by request. This is not in the public domain due to author's next project related to it.

\section{Ethics approval and consent to participate}

Ethical approval was obtained from Institutional Ethics Committee, AllMS, Bhubaneswar. Ref Number: T/IM-NF/CM\&FM/17/47. Written informed consent and assent was obtained from the participants.

\section{Consent for publication}

Not applicable.

\section{Competing interests}

None.

Received: 25 October 2019 Accepted: 27 April 2020

Published online: 06 May 2020

\section{References}

1. Statista. (2013-2019). Number of mobile phone users in India from 2013 to 2019 (in millions). [Available from: https://www.statista.com/statistics/27465 8/forecast-of-mobile-phone-users-in-india]. Accessed 12 Mar 2019.

2. The History and Evolutio of the Smartphone: 1992-2018. [Available from: https://www.textrequest.com/blog/history-evolution-smartphone]. Accessed 19 Sept 2019.

3. Dictionary, O. E. (2008). Oxford English Dictionary. [Available from: https://en. oxforddictionaries.com/definition/selfie]. Accessed 12 Mar 2019.

4. Word of the Year 2013 | Oxford Dictionaries. [Available from: https://en. oxforddictionaries.com/word-of-the-year/word-of-the-year-2013]. Accessed 12 Mar 2019.

5. Lee JA, Sung Y. Hide-and-Seek: Narcissism and "Selfie"-Related Behaviour. Cyberpsychology Behavior and Social Networking. 2016;19(5):347-51.

6. Mobile Technology and Home Broadband 2019. Majorities of Americans have a smartphone, subscribe to broadband, but this varies by education, income. Pew Research Center: Internet \& Technology. [Available from: https://www.pewresearch.org/internet/2019/06/13/mobile-technology-andhome-broadband-2019/pi_2019-06-13_broadband_0-03]. Accessed 25 Feb 2020.

7. Katz JE, Crocker ET. Selfies and photo messaging as visual conversation: Reports from the United States, United Kingdom and China. International Journal of Communication. 2015;9(12):1861-72.

8. Dutta E, Sharma P, Dikshit R, Shah N, Sonavane S, Bharati A, et al. Attitudes toward selfie taking in school-going adolescents: An exploratory study. Indian J Psychological Med. 2016;38(3):242-5.

9. Nagaraju R, Chikkegowda LK. Selfie: A Rising Culture. Assessment of Selfitis And Its Relation with Self-Esteem Among Medical and Nursing Students: A Cross-Sectional Study. National J Community Med. 2019;10(5):285-9.

10. Dokur M, Petekkaya E, Karadagi M. Media-based clinical research on selfierelated injuries and deaths. Turkish J Trauma Emerg Surg. 2017:24(2):129-35.

11. Flaherty GT, Choi J. The 'selfie'phenomenon: reducing the risk of harm while using smartphones during international travel. J Travel Med. 2016;23(2):1-3.

12. Gabriel F. Sexting, selfies and self-harm: Young people, social media and the performance of self-development. Media Int Australia. 2014;151(1):104-12.

13. Blog S. We dare you to take an underwater selfie. The Selfie Post 2018. [Available from: http://theselfiepost.com/underwater-selfie]. Accessed 22 Sept 2019.

14. SelfieHome - Apps on Google Play. [Available from: https://play.google.com/ store/apps/details?id=com selfiehome\&hl=en]. Accessed 22 Sept 2019.

15. Dangerous selfies have killed 259 people. BBC News 2018 Oct 4. [Available from: https://www.bbc.com/news/newsbeat-45745982]. Accessed 22 Sept 2019
16. Couple die while taking a selfie at a cliff edge in Yosemite National Park. Her.ie. [Available from: https://www.her.ie/news/couple-die-taking-selfie-cliffedge-america-433549]. Accessed 22 Sept 2019.

17. Bansal A, Garg C, Pakhare A, Gupta S. Selfies: A boon or bane? Journal of Family Medicine and Primary Care. 2018;7(4):828-31.

18. Jain MJ, Mavani KJ. A comprehensive study of worldwide selfie-related accidental mortality: a growing problem of the modern society. Int I Injury Control Safety Promotion. 2017;24(4):544-9.

19. Senft TM, Baym NK. What does the selfie say? Investigating a global phenomenon. Int J Commun. 2015;9(19):1588-606.

20. Balakrishnan J, Griffiths MD. An Exploratory Study of "Selfitis" and the Development of the Selfitis Behaviour Scale. Int J Mental Health Addiction. 2018;16(3):722-36

21. Regression: Methods SPSS. [Available from: http://www.unige.ch/ses/sococ/ cl/spss/cmd/regression.methods.html]. Accessed 26 Sept 2019.

22. Wild C. The first selfie ever was taken in 1839. [Available from: https:// mashable.com/2014/11/07/first-selfie]. Accessed 28 Sept 2019.

23. Dhir A, Pallesen S, Torsheim T, Andreassen CS. Do age and gender differences exist in selfie-related behaviours? Comput Human Behaviour. 2016:63:549-55.

24. Nasar J, Hecht P, Wener R. Mobile telephones, distracted attention, and pedestrian safety. Accident Analysis Prevention. 2008:40(1):69-75.

25. Kela R, Khan N, Rashi S, Bisma A. Selfie: Enjoyment or Addiction? J Med Sci Clin Res. 2017:5(1):15836-40.

26. Sorokowski P, Sorokowska A, Oleszkiewicz A, Frackowiak T, Huk A, Pisanski K. Selfie posting behaviours are associated with narcissism among men. Personality Individual Differences. 2015;85:123-7.

27. Fox J, Rooney MC. The Dark Triad and trait self-objectification as predictors of men's use and self-presentation behaviours on social networking sites. Personality Individual Differences. 2015;76:161-5.

28. Weafer J, Wit HD. Sex differences in impulsive action and impulsive choice. Addictive Behaviors. 2014 Nov;39(11):1573-9.

29. Trudy HHC, Leanne C. Follow me and like my beautiful selfies: Singapore teenage girls engagement in self-presentation and peer comparison on social media. ComputHuman Behavior. 2016:55(Part A):190-7.

30. Sung Y, Lee JA, Kim E, Choi SM. Why we post selfies: Understanding motivations for posting pictures of oneself. Personality Individual Differences. 2016;97:260-5.

31. Ries B. Russian government publishes guide to taking "safe selfies". [Available from: https://mashable.com/2015/07/07/russia-safe-selfies]. Accessed 28 Sept 2019.

32. Subramanian C. Saying No to Selfies at the Hong Kong Marathon. [Available from: http://newsfeed.time.com/2013/09/18/saying-no-to-selfies-at-thehong-kong-marathon]. Accessed 28 Sept 2019.

33. Scientists call for 'no selfie zones' after study finds hundreds have died in the past six years. [Available from: https://www.dailymail.co.uk/news/ article-6224579/Scientists-call-no-selfie-zones-study-finds-hundreds-diedpast-six-years.html]. Accessed 29 Sept 2019.

\section{Publisher's Note}

Springer Nature remains neutral with regard to jurisdictional claims in published maps and institutional affiliations.

Ready to submit your research? Choose BMC and benefit from:

- fast, convenient online submission

- thorough peer review by experienced researchers in your field

- rapid publication on acceptance

- support for research data, including large and complex data types

- gold Open Access which fosters wider collaboration and increased citations

- maximum visibility for your research: over $100 \mathrm{M}$ website views per year

At $\mathrm{BMC}$, research is always in progress.

Learn more biomedcentral.com/submission 